\title{
Reconstrucción de piel cabelluda (SCALP) con injerto de espesor parcial y expansor tisular secundario a mordedura de perro en paciente pediátrico
}

\author{
Reconstruction of SCALP with partial thickness graft and tissue \\ expander following a dog bite in a pediatric patient
}

\begin{abstract}
Carlos Altamirano Arcos ${ }^{1}$, Enrique Chávez Serna², Federico Iñigo Arroyo ${ }^{1}$, Laura Andrade Delgado³, Armando Guillermo Apellaniz Campo ${ }^{4}$, Andrea Carrillo Romero ${ }^{1}$, Federico Iñigo Muñoz ${ }^{5}$
\end{abstract}

\section{RESUMEN}

Introducción. Los defectos grandes y complejos de piel cabelluda en los pacientes pediátricos representan un reto para el cirujano plástico que se enfrenta a este tipo de lesiones, debido a la dificultad de las técnicas quirúrgicas disponibles en este grupo de edad. El objetivo primario en el manejo de este tipo de heridas es lograr una cobertura adecuada de la bóveda craneana, con el propósito fundamental de prevenir la exposición y desecación ósea y la sepsis. El objetivo secundario será el resultado estético, en el cual se buscará atenuar la alopecia y esconder las cicatrices.

Objetivo. El objetivo de este trabajo es dar a conocer el manejo quirúrgico para la reconstrucción de heridas complejas de cuero cabelludo en forma secuencial con buenos resultados estéticos.

Material y métodos. Se presenta el caso de masculino de 1 año quien fue víctima de mordedura de perro, presentando herida de espesor total en piel cabelluda en región parietooccipital, con pérdida de cobertura cutánea, reconstrucción primaria con injerto de espesor parcial y en segundo tiempo quirúrgico el uso de expansores tisulares con fines estéticos.

Resultados. Posterior a 8 meses con un total de 4 tiempos quirúrgicos (1- lavado quirúrgico, remodelación de bordes, avance de colgajos locales,toma y aplicación de injerto de espesor parcial con fijación por medio de sistema de presión negativa, 2- retiro de sistema de presión negativa, 3- colocación de expansores, 4- retiro de expansores, avance de colgajo occipital y cierre primario) se obtiene un resultado estético favorable.

Conclusiones. El manejo de heridas complejas en piel cabelluda en población pediátrica con injertos de espesor parcial ha demostrado eficacia al lograr una cobertura inmediata del defecto con menor morbilidad que otras técnicas, aún más cuando se apoyan de herramientas como el sistema de presión negativa. La reconstrucción posterior con expansores tisulares es aconsejable para lograr la disminución de secuelas.

Palabras claves: reconstrucción, paciente pediátrico, mordedura de perro, cirugía reconstructiva, piel cabelluda, injertos, expansor tisular, SCALP.

\begin{abstract}
Introduction. Large and complex scalp defects in pediatric patients represent a challenge for the plastic surgeon who faces this kind of injuries, due to the difficulty of the surgical techniques available in this age group. The primary goal in the management of this kind of wounds is to achieve adequate coverage of the cranial vault, with the main purpose of preventing bone exposure and sepsis. The secondary goal is to reach an aesthetic result, where alopecia can be attenuated, and the scars hidden.

Objective. The objective of this work is to present the sequential surgical management for the reconstruction of complex scalp wounds with adequate aesthetic results.

Material and methods. We present the case of a 1-year-old child who was bitten by a dog, presenting a full-thickness wound on the scalp in the parieto-occipital region, with skin coverage loss, primary reconstruction with a partial-thickness graft, and in the second surgical procedure, the use of tissue expanders for aesthetic purposes.

Results: After 8 months with a total of 4 surgical procedures (1- antisepsis, ed ges remodeling, local flaps advance, harvesting and application of partial thickness skin graft with negative pressure system, 2- removal of negative pressure system, 3- placement of tissue expanders, 4- removal of tissue expanders, occipital flap advance and primary closure) a favorable aesthetic result is obtained. Conclusions. The management of scalp complex wounds in the pediatric population with partial thickness skin grafts has demonstrated efficacy by achieving immediate coverage of the defect with lower morbidity than other techniques, even more when using tools such as the negative pressure system, subsequent reconstruction with tissue expanders is an option in order to achieve sequelae reduction.
\end{abstract}

Key words: reconstruction, pediatric patient, dog bite, reconstructive surgery, scalp, grafts, tissue expander, SCALP.

REVISTA ARGENTINA DE CIRUGÍA PLÁSTICA 2019;25(1):21-27. DOI/10.32825/RACP/201901/0021-0027

1. Residente de Cirugía Plástica y Reconstructiva, División de Cirugía Plástica y Reconstructiva, Hospital General Dr. Manuel Gea González, Secretaría de Salud.

2. Médico Pasante de Servicio Social en Investigación, División de Cirugía Plástica, Hospital General Dr. Manuel Gea González, Secretaría de Salud.

3. Jefe de la División de Cirugía Plástica y Reconstructiva, Hospital General Dr. Manuel Gea González, Secretaría de Salud.

4. Médico Adscrito de Cirugía Plástica y Reconstructiva, División de Cirugía Plástica y Reconstructiva, Hospital General Dr. Manuel Gea González, Secretaría de Salud.

5. Cirujano Plástico y Reconstructivo. Director de la Clínica ICEGER Cirugia Plástica y Reconstructiva, Ciudad de México, México.

$\triangle$ Correspondencia: Dr. Enrique Chávez Serna. Calz. de Tlalpan 4800 Belisario Domínguez Secc 16, 14080 Ciudad de México, CDMX. Tel: 2223231287.enrique.chavez.serna@gmail.com

Los autores no declaran conflictos de intereses

\section{INTRODUCCIÓN}

Las heridas por mordedura de perro continúan siendo un problema de salud de pública, abarcando una gran parte de las visitas a los servicios de urgencia. Se estima que ocurren alrededor de 120.000 casos anuales de mordedura de perro en México; sin embargo, estas cifras podrían estar subestimadas debido a la falta de registros por los servicios de salud ${ }^{1}$. La población pediátrica es la más afectada, ya que el $60 \%$ de los casos ocurre en menores de 18 años, en especial el grupo de edad comprendido entre 5-9 años, el cual reporta la mayor tasa de incidencia ${ }^{2}$. En cuanto a la distribución por gé- 

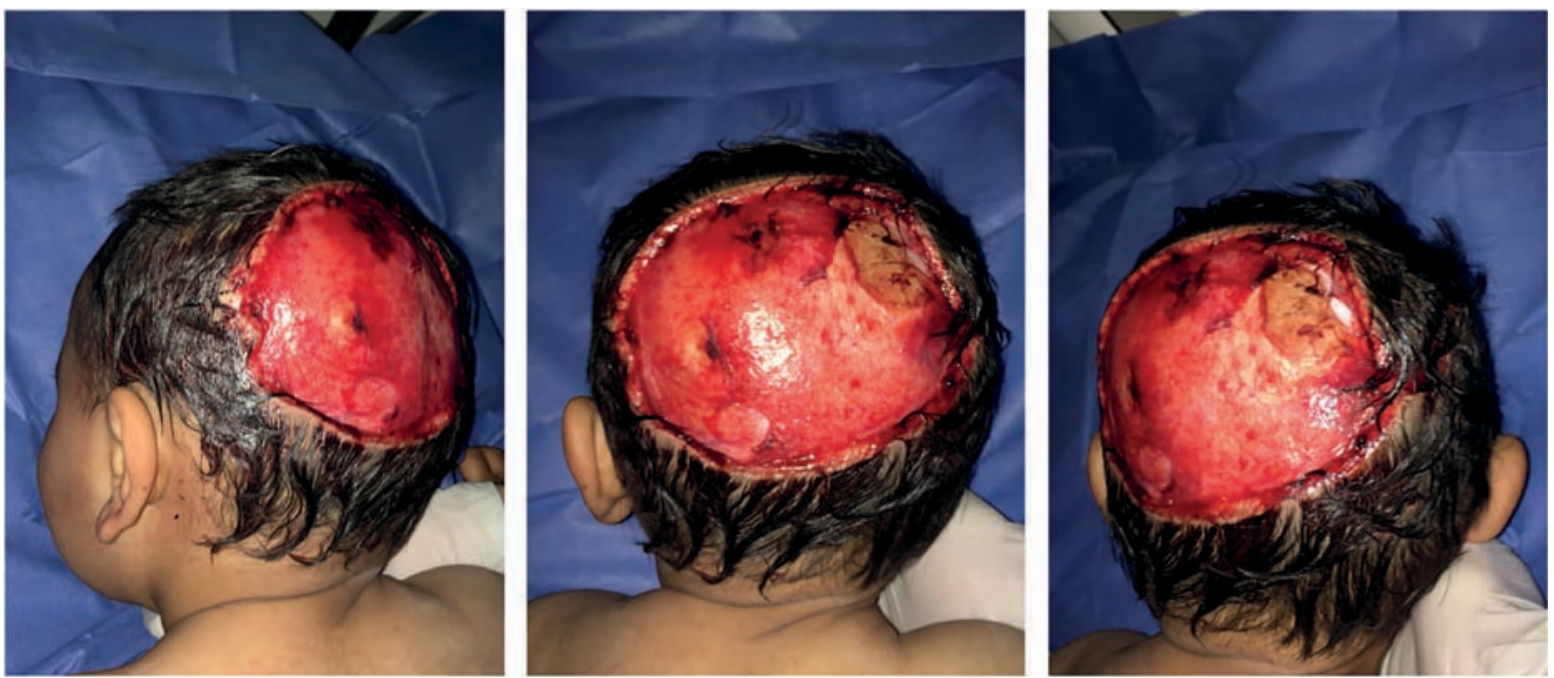

Figura 1. Herida Inicial.
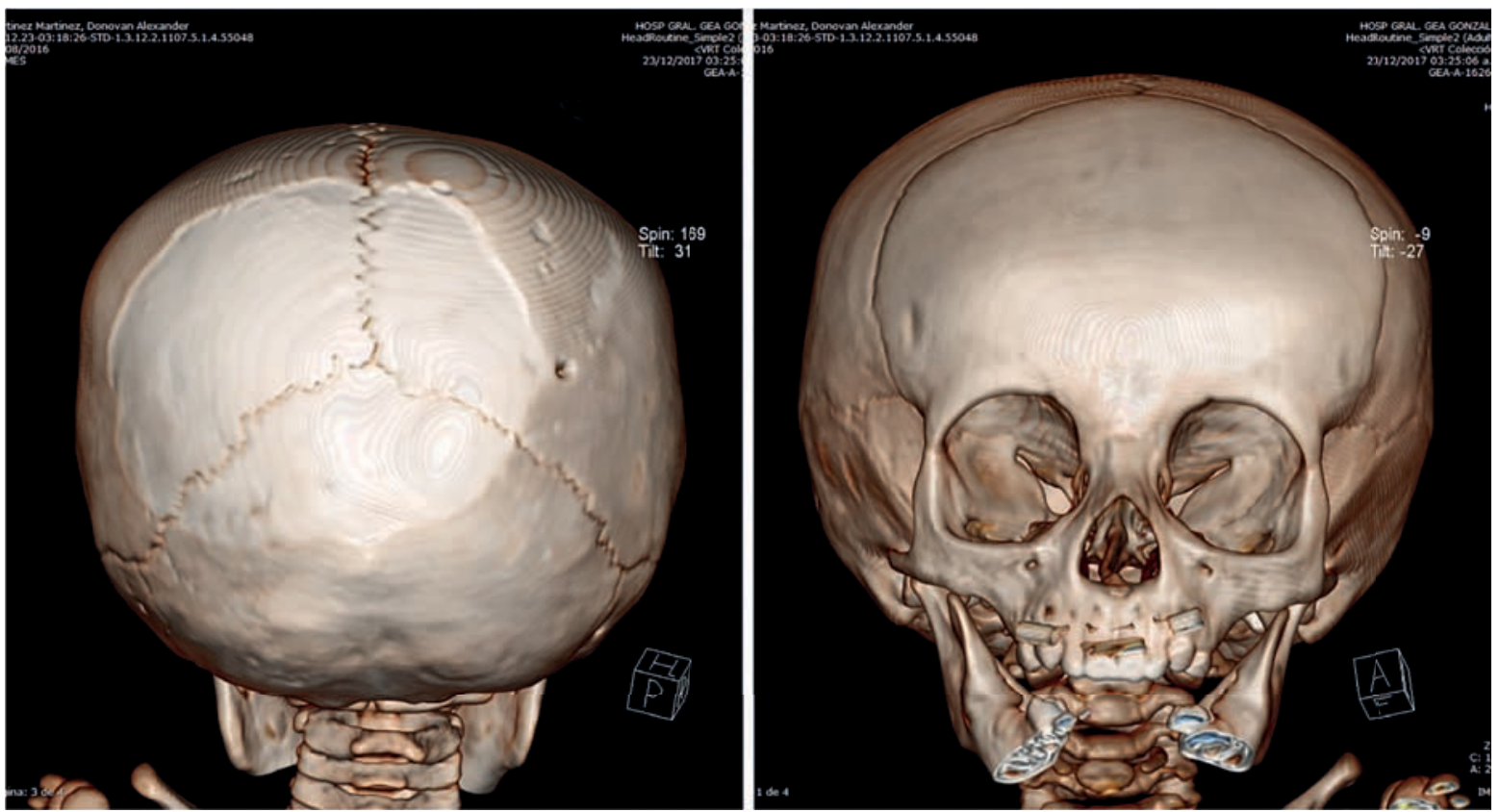

Figura 2. Tomografia de cráneo sin datos de fractura.

nero los hombres representan una ligera mayoría, sin existir una diferencia importante ${ }^{3}$. La zona anatómica afectada con más frecuencia es la cara, seguida de la piel cabelluda y el cuello, ello explicado por diversos factores, principalmente la estatura del niño, que permite el alcance del can a la cabeza del niño, comportamiento desinhibido que el niño demuestra hacia el perro, como sorprenderlo mientras se encuentra comiendo, o juego agresivo repetido, así como falta de desarrollo de habilidades motoras para proteger la cara, lo cual hace que la severidad de las lesiones sea más gra$\mathrm{ve}^{4,5}$. Sin embargo, las heridas complejas de la piel cabelluda (pérdida de solución de continuidad de piel, tejido subcutáneo, aponeurosis, tejido areolar, periostio y huesos de la bóveda craneana) por mordedura de perro generalmente ocurren en niños pequeños ( $0-3$ años), en donde el ataque no es atribuible a una causa espe- cífica. Se asocia con razas medianas o grandes de temperamento agresivo, principalmente la raza pitbull, la cual de acuerdo a nuestra experiencia institucional en la mayoría de los casos se asocia con heridas severas. Esta raza demuestra una actividad de caza importante debido al entrenamiento para pelea a la que es sometida y a las 1200 libras de fuerza que ejerce la mordida de estos canes. ${ }^{6}$

Estas lesiones requerirán un manejo especializado y prolongado en comparación con las mordeduras de perro convencionales, lo cual impacta en la morbilidad y en los costos que conlleva el tratamiento para evitar secuelas ${ }^{7,8}$. Los defectos grandes y complejos de la piel cabelluda en los pacientes pediátricos representan un reto para el cirujano plástico ya que se cuenta con una limitada variedad de técnicas quirúrgicas para poder proporcionar un pronós- 

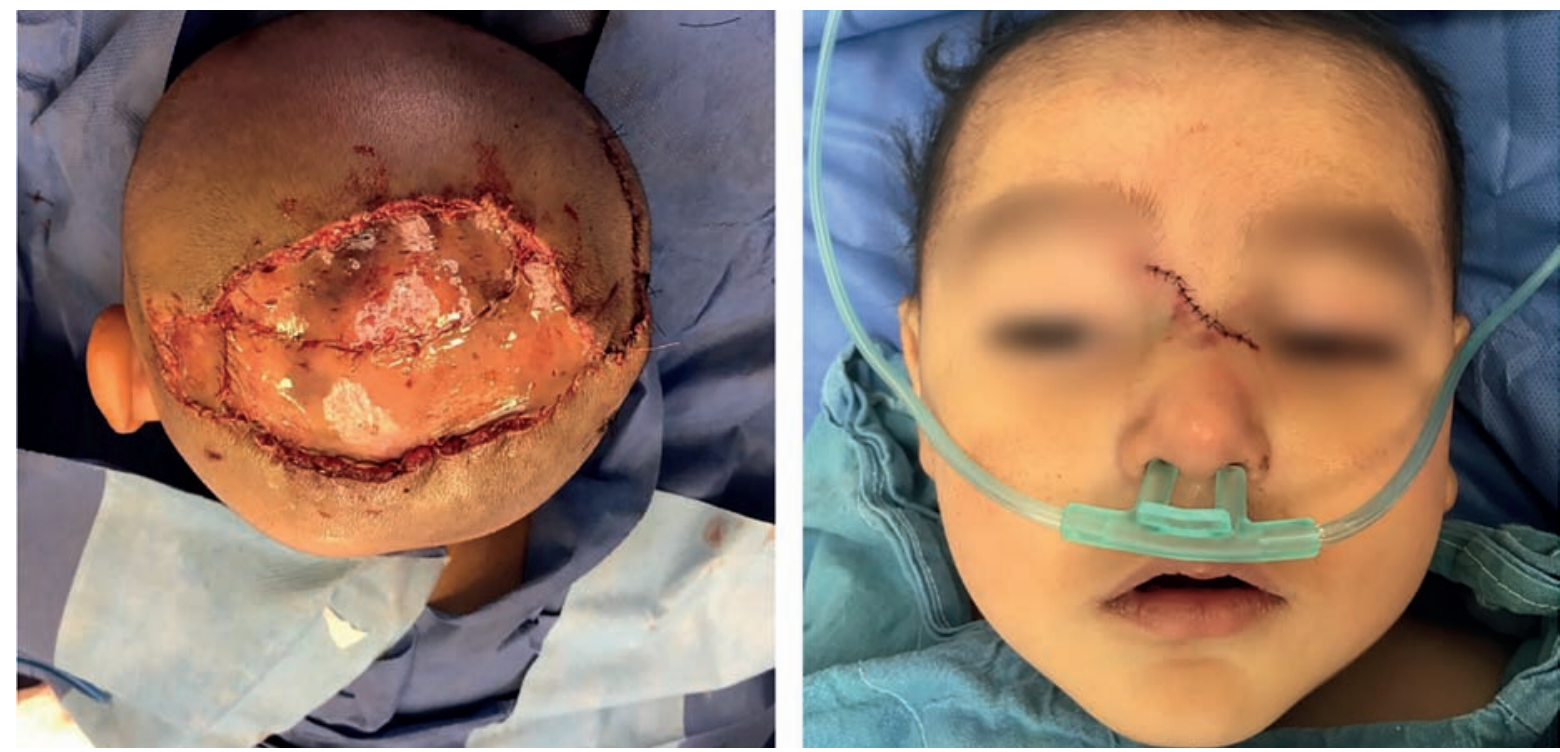

Figura 3. Avance de colgajos, Toma y aplicación de injerto.
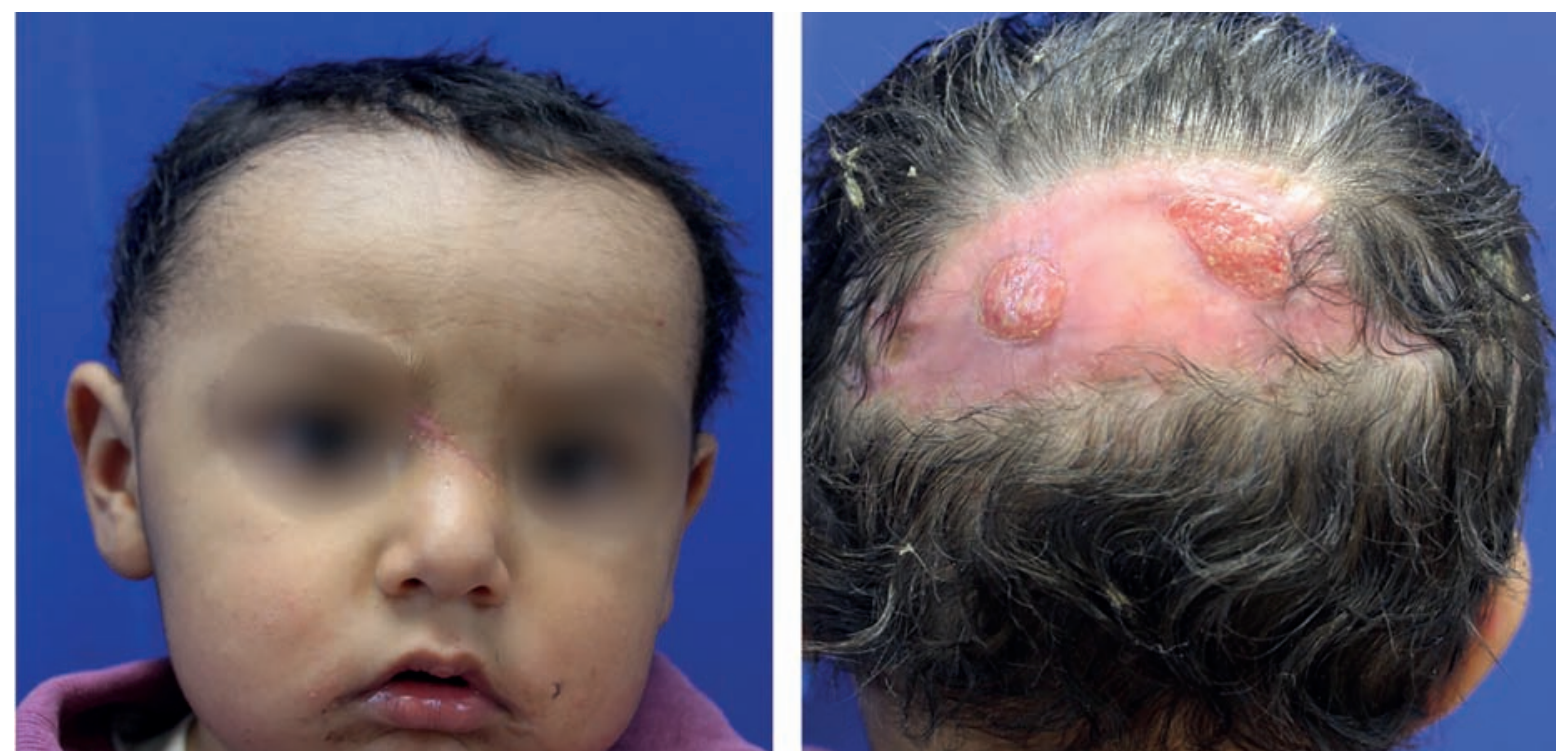

Figura 4. Secuelas 4 meses postoperatorio, se aprecia defecto cicatrizal y alopecia.

tico funcional y estético favorable?. El objetivo primario en el manejo de este tipo de heridas es lograr la cobertura primaria del defecto y de la bóveda craneana, con el propósito fundamental de prevenir la exposición y desecación ósea y la sepsis. Dentro de la escala reconstructiva podemos encontrar algunas opciones tales como injerto de piel, colgajos locales, transferencia de tejido libre, expansión de tejido y el uso de una matriz dérmica acelular seguida de injerto de piel ${ }^{10,11}$. El objetivo secundario será el resultado estético, en el cual se buscará atenuar las áreas alopécicas y las cicatrices, donde los expansores tisulares han demostrado su eficacia ${ }^{12,13}$. El propósito de este trabajo es dar a conocer el manejo empleado en este paciente pediátrico utilizando herramientas de la escala reconstructiva en secuencia para la reconstrucción de las heridas complejas de cuero cabelludo con buenos resultados estéticos.

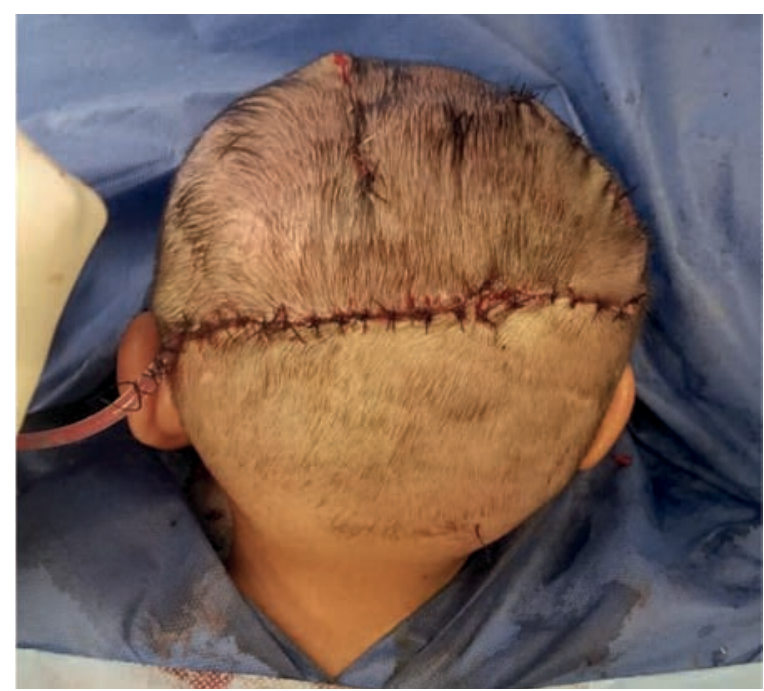

Figura 5. Colocación de expansores. 

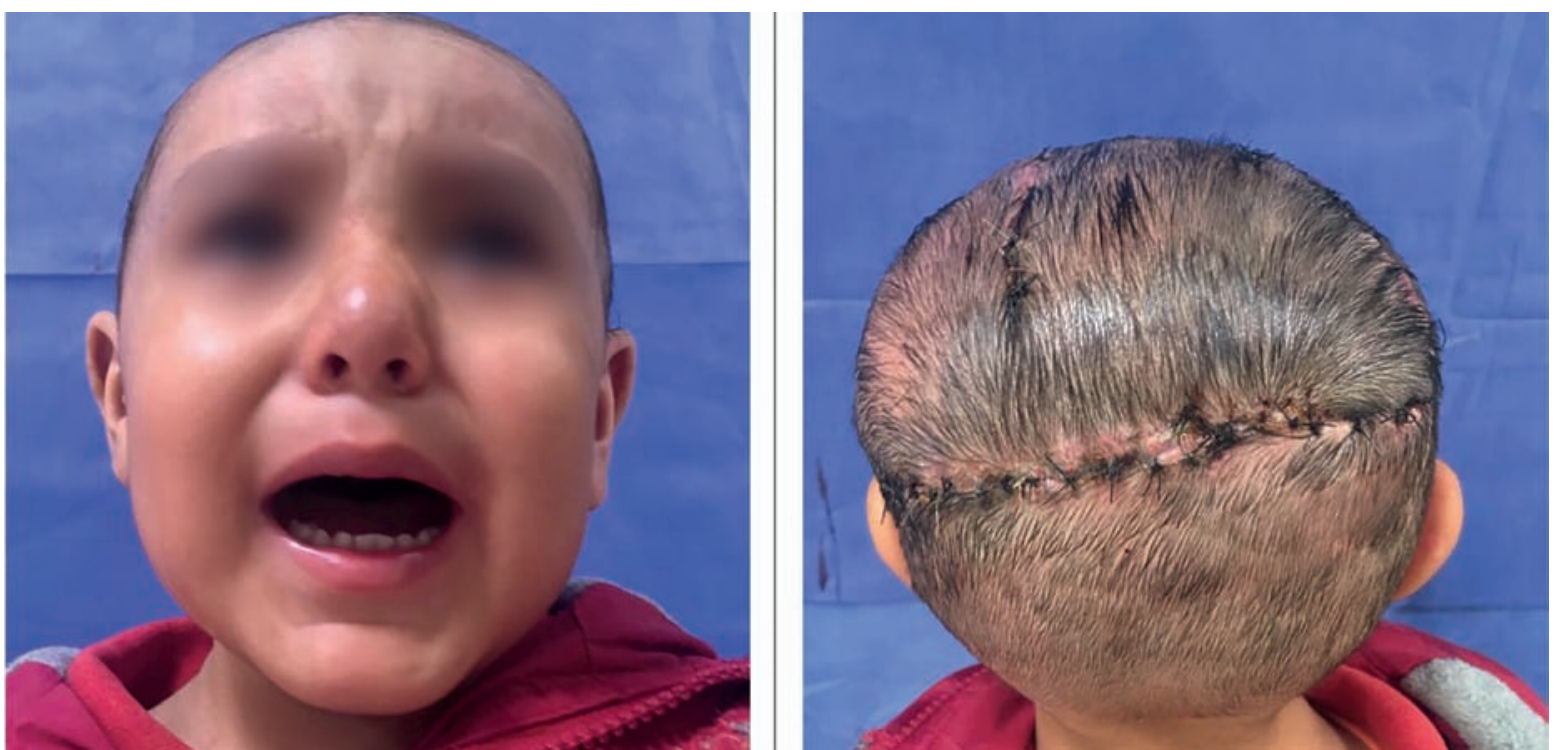

Figura 6. Retiro de expansores, Avance de colgajo occipital y cierre primario.
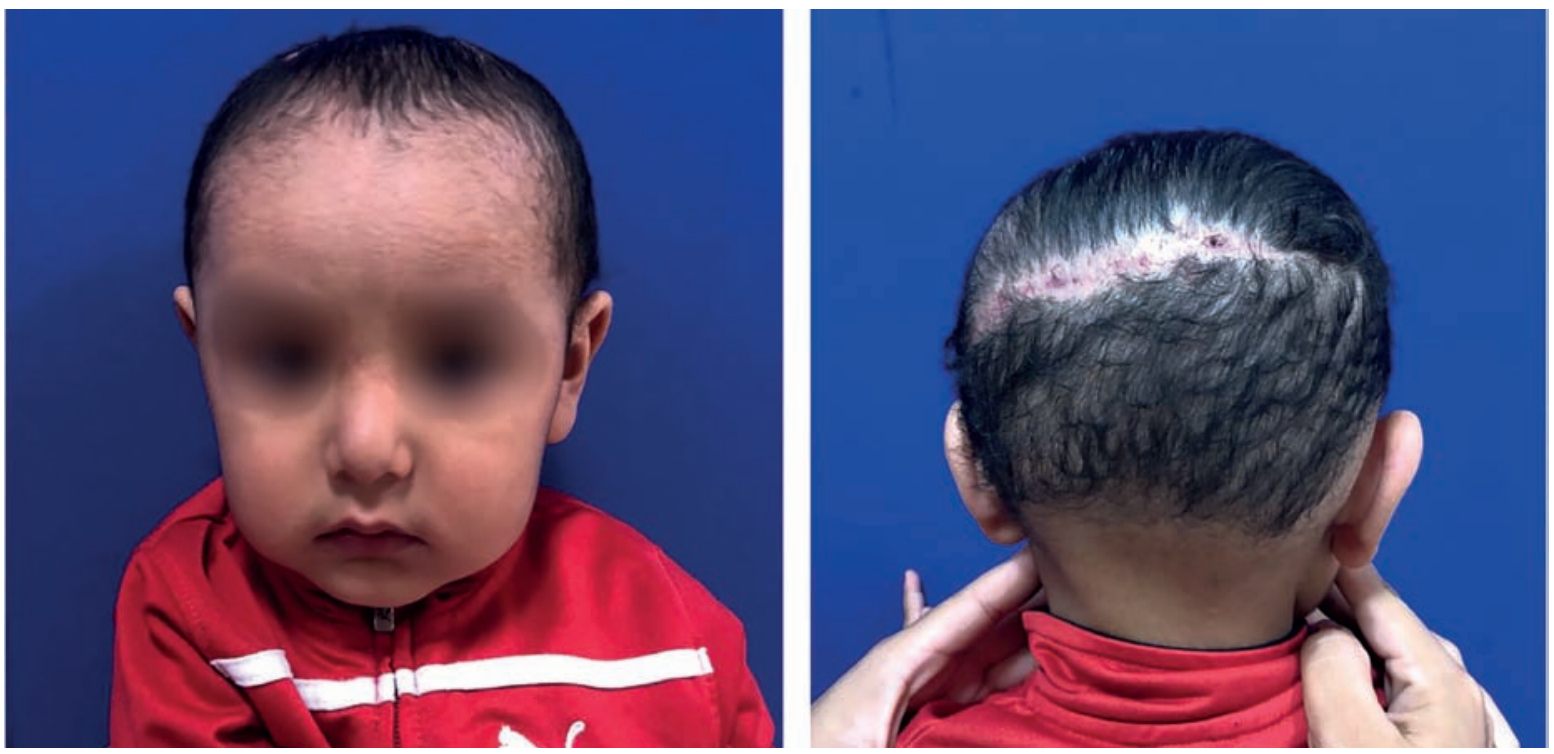

Figura 7. Resultado 8 meses posoperatorio vista frontal.

\section{CASO CLÍNICO}

Presentamos el caso de un lactante masculino de 1 año de edad, sin antecedentes de importancia, inmunizaciones completas, adecuado estado nutricional, quien sufre ataque por mordedura de perro conocido, raza pitbull, por lo cual acudió a Hospital de primer contacto, donde se realizó lavado y vendaje de la herida. Fue referido a nuestra Institución por la severidad de las lesiones y por no contar con Cirugía Plástica y Reconstructiva. A su llegada al área de Urgencias Pediatría con 9 horas de evolución, a la exploración física se encontró: herida cortante en dorso nasal de aproximadamente $5 \mathrm{~cm}$ que comprometía piel y tejido subcutáneo que fue desbridada, remodelada y manejada con cierre primario, más herida por avulsión con pérdida de cobertu- ra cutánea en región parietooccipital de aproximadamente $20 \times 15 \mathrm{~cm}$ que comprometía piel cabelluda, tejido celular subcutáneo, músculo y pericráneo (Figuras 1 y 2). Se ingresó a hospitalización, se iniciaron antibióticos profilácticos intravenosos (trimetoprima-sulfametoxazol más clindamicina) y se ingresó a quirófano para la reparación primaria del defecto. Se planeó para toma y aplicación de injerto, se realizó disección cefálica y caudal de herida parietooccipital, se realizó avance de bordes, los cuales fueron fijados hacia el periostio con vicryl 4-0. De manera simultánea se realizó toma de injerto de espesor parcial intermedio, se realizaron perforaciones en la tabla externa del cráneo a nivel del defecto en la zona parietooccipital para promover tejido de granulación, el injerto se fijó con vicryl 4-0 y se colocó sistema de presión negativa a $125 \mathrm{mmHg}$ con- 


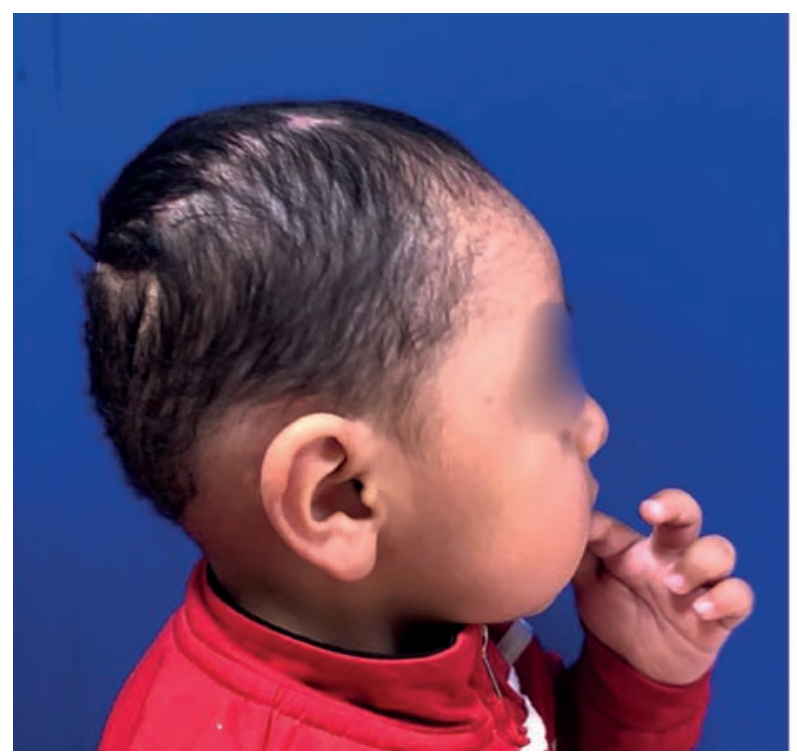

Figura 8. Resultado 8 meses postoperatorio vista lateral.

tinuo (Figura 3). El paciente cursó con adecuada evolución intrahospitalaria, cinco días posteriores al primer tiempo quirúrgico ingresa a quirófano para retiro de sistema de presión negativa, encontrando injerto integrado adecuadamente. Se egresa al día siguiente por adecuada evolución y se envió a la consulta externa para seguimiento de secuelas. Luego de 6 meses se realizó la colocación de expansores por encontrarse alopecia cicatrizal (Figura 4). Bajo anestesia general se realiza incisión perpendicular al defecto a nivel de sutura metópica de $4 \mathrm{~cm}$, se realizó bolsillo a cada lado y se colocaron expansores en plano subgaleal para minimizar el riesgo de sangrado de $35 \mathrm{cc}$ izquierdo de $4 \times 2,5 \times 3,5 \mathrm{~cm}$ y válvula temporal izquierda, y otro expansor rectangular de $25 \mathrm{cc}$ derecho de $3,5 \times 2,5 \times 4 \mathrm{~cm}$ y válvula temporal derecha, ambos se expandieron previamente con 5 cc de solución fisiológica, se realizó cierre y colocación de vendaje. Seis semanas posteriores, el paciente acudió por presentar exposición de expansor, por lo que ingresa a quirófano, se realiza incisión coronal en borde de defecto alopécico, disección y retiro de expansores más disección de colgajo hacia región parietal y en borde inferior hacia occipital, se colocó drenaje tipo biovac, el cual se extrajo por contraabertura, se fijó a piel con seda 2-0 y se realizó afrontamiento de bordes con vicryl 2-0 y nylon 2-0 mediante puntos simples (Figuras 5 y 6). Cursó con adecuada evolución, se retiró drenaje y se decidió su egreso a los 2 días. El posoperatorio a los 8 meses se ve en las Figuras 7 y 8 .

\section{DISCUSIÓN}

La reconstrucción de heridas complejas con pérdida de cobertura en la piel cabelluda o heridas en SCALP por su mnemotecnia en inglés (Skin, subCutaneous tissue, galea Aponeurotica, Loose areolar tis-

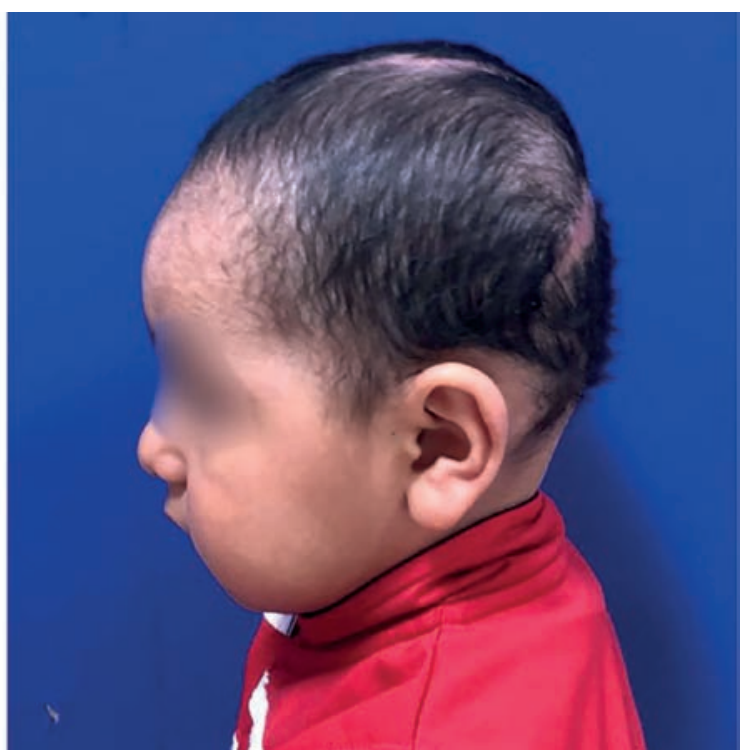

sue, and Pericranium) como suelen ser denominadas, son aquellas heridas que incluyen pérdida de solución de continuidad de piel, tejido subcutáneo, aponeurosis, tejido areolar, periostio y en ocasiones huesos de la bóveda craneana ${ }^{14}$. La mayoría de estas lesiones son causadas por traumatismos o accidentes de alto impacto. En los niños las mordeduras de perro representan una gran proporción en el mecanismo de esta afección ${ }^{15}$. El manejo de estas heridas a cualquier edad constituye un reto para el cirujano plástico, que cuenta con una cantidad limitada de procedimientos para su reparación, todos encaminados en primera instancia a lograr una cobertura del defecto primario.

En niños pequeños (lactantes, preescolares) la poca superficie de piel con la que cuentan, debido al mayor diámetro del cráneo en relación con el tórax y extremidades, hacen que la gama de técnicas quirúrgicas disponibles sea aún menor ${ }^{9}$. Para la reparación primaria en cuanto a cobertura de la bóveda craneana respecta, la técnica quirúrgica más empleada es la toma y aplicación de injerto, la cual ha demostrado resultados atractivos, mejor durabilidad y funcionalidad, siempre y cuando la toma del injerto del sitio donante tenga la superficie necesaria, ya que en ocasiones se necesitarán dos sitios donantes, aumentando la morbilidad del paciente pediátrico. Otras técnicas descritas como colgajos locales (dorsal ancho, colgajo del muslo anterolateral, antebrazo radial), transferencia de tejidos libres, uso de una matriz dérmica acelular seguida de injerto de piel han sido propuestos con resultados variables. No existe un consenso establecido sobre la técnica quirúrgica ideal, por lo que la misma deberá ser individualizada en cada caso ${ }^{15,16}$. Toda mordedura de perro debe ser considerada como una herida contaminada con potencial riesgo de causar infección en el sitio quirúrgico o diseminarse a estructuras adyacentes causan- 
do enfermedad sistémica, lo cual hace aún más difícil su manejo, requiriendo de vigilancia continua en hospitalización, colocación de drenajes y antibióticos sistémicos con el propósito de evitar complicaciones. La terapia antibiótica deberá estar dirigida contra las bacterias más comúnmente asociadas a la flora canina como Pasteurella multocida, especies de Staphylococcus y anaerobios ${ }^{17}$. En la era del sistema de presión negativa es aconsejable apoyarse de esta valiosa herramienta en la medida en que se cuente con ella, la cual, como sucedió en este caso, proporciona fijación del injerto, evita fuerzas de cizallamiento, lo mantiene húmedo y libre de acúmulo de líquidos que pudieran favorecer el desarrollo de biofilm, proliferación de microrganismos y como consecuencia la falta de integración o pérdida de este, proporcionando excelentes resultados ${ }^{18}$. En 1969, Belloste propuso realizar perforaciones a la tabla externa del cráneo para promover tejido de granulación como parte del tratamiento de lesiones en piel cabelluda. En 1871, Netolitzky popularizó la colocación de injertos dérmicos sobre el tejido de granulación para promover una mejor cicatrización ${ }^{19}$. Utilizando estas dos técnicas se logró alcanzar una adecuada integración del injerto en el defecto tratado. Una vez que la reconstrucción primaria ha sido realizada con éxito, se debe buscar el mejor resultado estético posible, ya que en los niños este evento marcará su vida y las secuelas físicas, funcionales y psicológicas repercutirán en la calidad de vida posterior. El concepto de expansores tisulares en Cirugía Plástica y Reconstructiva comenzó en la década de 1950 cuando Neumann publicó sus resultados de usar un globo para estirar la piel en la zona postauricular y luego usar esta piel estirada para la reconstrucción del pabellon auricular ${ }^{20}$.

El cuero cabelludo es un lugar ideal para la expansión tisular debido a la rica circulación sanguínea, el tejido grueso y una base reforzada. El beneficio más importante es que la expansión del tejido proporciona un cuero cabelludo con cabello natural con una densidad de cabello cercana a la normal ${ }^{21}$.

En la actualidad, se considera que un área de alopecia de hasta el $50 \%$ o más de la superficie total del cuero cabelludo se puede reparar mediante la expansión tisular (expansión tisular en etapas múltiples o expansión tisular en serie). Aproximadamente el $50 \%$ del SCALP puede ser reconstruido solo con expansores tisulares ${ }^{22}$.

Debido a que la expansión del tejido ejerce una cantidad considerable de fuerza sobre los tejidos, algunos cirujanos prefieren colocarlos una vez que la herida se ha estabilizado. El tamaño de la base del implante debe ser 2,5 veces el área del defecto ${ }^{23}$.

Los expansores se llenan aproximadamente entre el
$10 \%$ y el $20 \%$ de su volumen de manera inicial para permitir una mejor hemostostasis a través de la presión. La expansión se inicia después de la segunda semana posoperatoria. La prótesis se infla cada 5 a 7 días con solución salina hasta que se logre una adecuada cantidad de tejido ${ }^{24}$.

Tal como se presenta en el caso, la técnica de colocación y el número de expansores a utilizar deben ser individualizados para cada paciente. Estos se irán expandiendo semanalmente hasta que se cuente con suficiente superficie cutánea para lograr la cobertura. Una de las complicaciones más frecuentes es la exposición del material expansor, la cual debe ser resuelta con el retiro inmediato y cierre primario ${ }^{12,13}$. El seguimiento estricto de este tipo de pacientes es necesario para lograr resultados funcionales adecuados, disminuir el riesgo de infección y la mortalidad. Posteriormente el manejo deberá enfocarse en el resultado estético que logrará integrar al paciente a una vida lo más normal posible. Este tipo de heridas a menudo necesitarán múltiples intervenciones para lograr un resultado satisfactorio. El uso de los injertos de espesor parcial demuestra su beneficio en la cobertura primaria en comparación de otras técnicas; asimismo, el uso de expansores tisulares sigue siendo una herramienta vital para disminuir las secuelas estéticas ${ }^{15,16,20}$. El reporte del manejo en este paciente demuestra que las técnicas son reproducibles y se pueden asociar a los recursos actuales como el sistema de presión negativa para la reparación de heridas complejas en la piel cabelluda (SCALP). En adición, esta técnica quirúrgica es más fácil y rápida de realizar con menos comorbilidades que otras técnicas descritas.

\section{CONCLUSIONES}

Los injertos de espesor parcial en población pediátrica han demostrado su eficacia al lograr una cobertura inmediata del defecto con menor morbilidad que otras técnicas en cirugía plástica, además de ser más reproducibles para la reconstrucción de la piel cabelluda con resultados favorables. Es importante que el cirujano que se enfrenta a este tipo de heridas se apoye en las herramientas actuales como el sistema presión negativa para brindar el mejor pronóstico posible. El defecto alopécico es fácilmente manejado con expansores tisulares, los cuales tienen pocas complicaciones, resuelven el defecto en su mayor proporción y son fáciles de manejar. Las heridas complejas de la piel cabelluda en el paciente pediátrico requieren experiencia en cirugía reconstructiva. Este caso muestra una excelente resolución y puede ser empleado como referencia para obtener resultados similares. 


\section{BIBLIOGRAFÍA}

1. Dirección General de Epidemiología. Anuarios de Morbilidad 20142017. Sistema Único de Información para la vigilancia Epidemiológica. DGAE/SSA [citado el 20 de agosto de 2018] disponible en: http:// www.epidemiologia.salud.gob.mx/anuario/html/anuarios.html.

2. Hernández Arroyo DA. Mordedura de perro: Enfoque epidemiológico de las lesiones causadas por mordedura de perro. Revista de Enfermedades Infecciosas en Pediatría. Septiembre 2009. Vol. XXIII Núm. 89;13-20.

3. Kaye $A E$, Belz JM, Kirschner RE. Pediatric dog bite injuries: a 5-year review of the experience at the Children's Hospital of Philadelphia. Plast Reconstr Surg 2009;124(2):551-558.

4. Velázquez Reyes V. Flores Ávila G, Pedroso Balandrano. A. Treatment of craniofacial region wounds caused by dog bite. Revista Odontológica Mexicana. December 2013. 17-4; 243-250.

5. Chen HH, Neumeier AT, Davies BW, Durairaj VD. Analysis of Pediatric Facial Dog Bites. Craniomaxillofac Trauma Reconstruction Craneomaxilofacial 2013;6(4):225-32.

6. Alizadeh K, Shayesteh A, Li Xu, M. An Algorithmic Approach to Operative Management of Complex Pediatric Dog Bites: 3-Year Review of a Level I Regional Referral Pediatric Trauma Hospital. Plastic and Reconstructive Surgery Global Open, 2017; 1-6.

7. Garvey EM, Twitchell DK, Ragar R, Egan JC, Jamshidi R. (2014). Morbidity of pediatric dog bites: A case series at a level one pediatric trauma center. J Pediatr Surg. 2015 Feb;50(2):343-6.

8. O'Brien DC, Andre TB, Robinson AD, Squires LD, Tollefson TT. Dog bites of the head and neck: an evaluation of a common pediatric trauma and associated treatment. Am J Otolaryngol. 2015;36:32-38.

9. Macedo JL, Rosa SC, Queiroz MN, Gomes TG. Reconstruction of face and scalp after dog bites in children. Rev Col Bras Cir. 2016 Dec;43(6):452-457.

10. Mcheik JN, Vergnes $P$, Bondonny JM. Treatment of facial dog injuries in children: a retrospective study. J Pediatr Surg. 2000;35(4):580-3.

11. Fleisher GR. The management of bite wounds. N Engl J Med. 1999; 340(2): 138-40.

12. Lee S, Rafii AA, Sykes J. Advances in scalp reconstruction. Curr Opin Otolaryngol Head Neck Surg 2006;14:249-253.
13. Disa JJ, Pusic AL, Hidalgo DH, et al. Simplifying microvascular reconstruction: a rational approach to donor site selection. Ann Plast Surg 2001:47:385-389

14. Desai SC, Sand JP, Sharon JD, Branham G, Nussenbaum B. Scalp reconstruction: an algorithmic approach and systematic review. JAMA Facial Plast Surg. 2015 Jan-Feb;17(1):56-66.

15. Fischer JP, Sieber B, Nelson JA, Kovach SJ, Taylor JA, Serletti JM. et. al. A 15-year experience of complex scalp reconstruction using free tissue transfer-analysis of risk factors for complications. J Reconstr Microsurg. 2013 Feb;29(2):89-97.

16. Gurtner GC, Evans GRD. Advances in head and neck reconstruction. Plast Reconstr Surg 2000;106:672-682

17. Meyers B, Schoeman JP, Goddard A, Picard J. The bacteriology and antimicrobial susceptibility of infected and non-infected dog bite wounds: fifty cases. Vet Microbiol 2008 Mar 18; 127 (3-4): 360-8.

18. Ali Z, Anjum A, Khurshid L, Ahad H, Maajid S, Dhar SA. Evaluation of low-cost custom made VAC therapy compared with conventional wound dressings in the treatment of non-healing lower limb ulcers in lower socio-economic group patients of Kashmir valley. J Orthop Surg Res. 2015 Dec 10;10:183.

19. Tan B-K, Por $Y-C$, Chen H-C. Complications of Head and Neck Reconstruction and Their Treatment. Seminars in Plastic Surgery. 2010;24(3):288-98.

20. Neumann, C. G. The expansion of an area of skin by progressive distension of a subcutaneous balloon. Plast. Reconstr. Surg. 19: 124, 1957

21. Fan, J., \& Yang, P. (1997). Aesthetic reconstruction of burn alopecia by using expanded hair-bearing scalp flaps. Aesthetic plastic surgery, 21(6), 440-444.

22. Leedy, J. E., Janis, J. E., \& Rohrich, R. J. (2005). Reconstruction of acquired scalp defects: an algorithmic approach. Plastic and reconstructive surgery, 116(4), 54e-72e.

23. Baker, S. R., \& Swanson, N. A. (1990). Tissue expansion of the head and neck: indications, technique, and complications. Archives of Otolaryngology-Head \& Neck Surgery, 116(10), 1147-1153.

24. Wagh, M. S., \& Dixit, V. (2013). Tissue expansion: Concepts, techniques and unfavourable results. Indian journal of plastic surgery: official publication of the Association of Plastic Surgeons of India, 46(2), 333. 